\title{
Study of Clinico Pathological Correlation in Autoimmune Bullous Disorders.
}

\author{
Nageswaramma.S ${ }^{1}$,D.S.S Srinivas Prasad ${ }^{2}$,P.V.Sivaram Sandeep ${ }^{3}$ \\ Department Of Dermatology, Venerology, Leprosy, Guntur Medical College, Guntur
}

\begin{abstract}
Background: Immune mediated vesiculobullous diseases can be diagnosed by close attention to the clinical details, histological confirmation and the clinical setting of the blistering. Confirmatory studies such as immunofluorescence will help in diagnosis of cases where histopathological features alone are not diagnostic. To evaluate clinical findings in association with histopathological findings, to study the histopathological findings in various immunobullous lesions of skin, and to confirm with immunofluorescence wherever possible Aim: The aim is to study histopathology of various Autoimmune vesicobullous disorders and its correlation with clinical evaluation in patients attending DVL department, Guntur medical college. Material \& Methods : A total of 80 patients of various bullous disorders attending to department of DVL in one and half year period from July 2015 to december 2016 were analysed. of these females (44), males (33), and (3) were children.The clinical features and histopathology were correlated for the diagnosis and direct immunofluorescence (DIF) was done whenever necessary.

Results: out of 80 patients we studied, females were 44( $55 \%)$, males 33(41.25\%), children $3(3.75 \%)$. 40 to 50 yrs age group were more commonly affected .we studied \& correlated histopathology and DIF with clinical findings, of these 43 patients (53.7\%) were pemphigus vulgaris. 18 (22.6\%) were bullous pemphigoid. 4 were $(2.51 \%)$ Dermatitis herpetifiormis, $2(2.51 \%)$ were pemphigus vegetans, 5 were pemphigus foliaceous $(6.25 \%), 3$ were CBDC (3.72\%).

Discussion \& Conclusion : Histopathology findings were correlated with clinical diagnosis in majority $(95.5 \%)$ of autoimmune bullous disorders except few cases (5.25\%) where diagnosis is done by immunoflourescence findings. To conclude, the correlation between clinical findings, Histopathology and Immunofluroscence plays a predominant role to confirm the atypical appearance of autoimmune blistering diseases.
\end{abstract}

\section{Introduction}

The bullous diseases have a history as old as that of medicine. Although blisters have drawn attention of medical caregivers throughout written history, only modern times have seen the origin of a clear classification of these diseases, based upon clinical and histological criteria. By close attention to the clinical details, histological confirmation and the clinical setting of the blistering a correct diagnosis can be achieved. Confirmatory studies such as immunofluorescence will help in diagnosis of cases where histopathological features alone are not diagnostic

\section{Materials And Methods}

The present study constitutes clinicopathological evaluation of primary vesiculobullous lesions of skin. 80 cases of vesiculobullous disorders wherse diagnosed in the department of DVL GGH Guntur, during the study period of one and half years.

A detailed history with particular reference to the mode of onset, characteristics and distribution of the lesions was taken. Histopathological evaluation of biopsies was done. Biopsy material was sent in $10 \%$ formalin. Immunofluorescence was done wherever possible.

Clinical data was recorded in the form of :

$>$ Detailed clinical history .

$>$ General \& dermatological examination .

$>$ Routine investigations.

$>$ Tzanck smear for Acantholytic cells.

$>$ After taking written informed consent of the patients, two biopsies were performed one from the fully developed vesicobullous lesion (lesional biopsy) for histopathological examination.

$>$ The other from the perilesional skin area with in $2 \mathrm{~cm}$ of diameter of lesion (perilesional biopsy) for Direct immunofluroscence whenever necessary. 


\section{Results}

Table 1 . distribution of various immunobullous disorders.

\begin{tabular}{|l|l|l|}
\hline SL No & Disorder & No. oF Cases \\
\hline 1 & Pemphigus Vulgaris & 45 \\
\hline 2 & Bullous pemphigoid & 19 \\
\hline 3 & Pemphigus Vegetens & 2 \\
\hline 4 & Dermatitis herpetiformis & 5 \\
\hline 5 & Pemphigus foliaceous & 6 \\
\hline 6 & Chronic bullous disorder of childhood & 3 \\
\hline Total & & 80 \\
\hline
\end{tabular}

we studied \& correlated histopathology and DIF with clinical findings, of these 43 patients $(53.7 \%)$ were pemphigus vulgaris. $18(22.6 \%)$ were bullous pemphigoid. 4 were $(2.51 \%)$ Dermatitis herpetifiormis, $2(2.51 \%)$ were pemphigus vegetans, 6 were pemphigus foliaceous $(6.25 \%)$, 3 were CBDC ( $3.72 \%) .4(5.25 \%)$ showed inconsistent results between clinical findings and histopathological findings for which immunoflourescence was done..

out of 80 patients we studied, females were 44( $55 \%)$, males 33(41.25\%), children 3 $(3.75 \%)$.

Table 2 - Sex wise distribution of immunobullous disorders

\begin{tabular}{|l|l|l|l|l|}
\hline \multirow{2}{*}{ TYPE } & MALES & PEMAntage & Number & Percentage \\
\cline { 2 - 5 } & Number & 21.25 & 28 & 35.25 \\
\hline Pemphigus vulgaris & 17 & 11.25 & 10 & 12.52 \\
\hline Bullous pemphigoid & 9 & 5.23 & 1 & 1.25 \\
\hline Dermatitis herpetiformis & 4 & 0 & 2 & 2.52 \\
\hline Pemphigus vegetens & 0 & 3.75 & 3 & 3.75 \\
\hline Pemphigus foliaceous & 3 & 1.25 & 2 & 2.52 \\
\hline CBDC & 1 & 42.73 & 46 & 57.27 \\
\hline total & 34 & & & \\
\hline
\end{tabular}

Table 3 - Age Wise Distribution Of Immunobullous Disorders

\begin{tabular}{|l|l|l|l|l|l|l|l|l|l|}
\hline Type & $\mathbf{0 - 1 0}$ & $\mathbf{1 1 - 2 0}$ & $\mathbf{2 1 - 3 0}$ & $\mathbf{3 1 - 4 0}$ & $\mathbf{4 1 - 5 0}$ & $\mathbf{5 1 - 6 0}$ & $\mathbf{6 1 - 7 0}$ & $\mathbf{7 0}$ & total \\
\hline $\begin{array}{l}\text { Pemphigus } \\
\text { vulgaris }\end{array}$ & & & 2 & 10 & 25 & 4 & 3 & 1 & 45 \\
\hline $\begin{array}{l}\text { Bullous } \\
\text { pemphigoid }\end{array}$ & & & & & 5 & 7 & 3 & 4 & 19 \\
\hline $\begin{array}{l}\text { Dermatitis } \\
\text { herpetiformis }\end{array}$ & & 1 & 2 & 2 & & & & 5 \\
\hline $\begin{array}{l}\text { Pemphigus } \\
\text { vegetens }\end{array}$ & & & & 2 & & & & & 2 \\
\hline $\begin{array}{l}\text { Pemphigus } \\
\text { foliaceous }\end{array}$ & & & & 1 & 2 & 2 & 1 & & 6 \\
\hline CBDC & 1 & 2 & & & & & & & 3 \\
\hline total & 1 & 2 & 3 & 15 & 34 & 13 & 7 & 5 & 80 \\
\hline
\end{tabular}

40 to 50 yrs age group were more commonly affected with immunobullous disorders.

Pemphigus vulgaris ( 25), bullous pemphigoid (5), dermatitis herpetiformis (2), pemphigus vegetens (2) cases was seen in our study. Increased cases of Bullous pemphigoid was seen in 51-60 years of age group. Pemphigus vulgaris was seen in 41-50 years of age group.

\section{Discussion}

The diagnosis of autoimmune bullous disease was based on evaluation of Clinical findings with corelation to Histopathology The most frequent disorder in our study was pemphigus vulgaris followed by bullous pemphigoid, Cases of limited number in our study were pemphigus foliaceous, pemphigus vegetans, CBDC, Dermatitis herpetiformis. Male to female ratio was $\underline{1: 1.7}$ which is comparable to the findings of Shamim et al, Archana et al. 40 to $60 \mathrm{yrs}$ age group were more commonly affected Majority of the lesions in pemphigus vulgaris were distributed in the oral cavity (44\%) followed by trunk (38\%) and extremities (33\%). Most of them were flaccid bullae (90.9\%) situated on a non erythematous base. The lesions in bullous pemphigoid were situated in the extremities in $62.5 \%$ followed by chest in $50 \%$ and were associated with itching in $55.4 \%$ of the cases. Most of them were tense bullae (90.9\%) situated on erythematous base.

Out of 45 cases of pemphigus vulgaris studied clinically, 44 of them showed consistent results with biopsy features showing suprabasal bulla (94.4\%) with neutrophils, eosinophils and acantholytic cells which has 
been documented in many other studies. 1 out of 45 showed nonspecific features for which DIF was done and showed IgG positivity in ICS in fishnet pattern in $80 \%$.

Bullous pemphigoid affects the elderly during $5^{\text {th }}$ to $7^{\text {th }}$ decade of life, with an average age of onset being $65 y$ ys. In our study, out of 19 cases of bullous pemphigoid studied clinically , 18 cases showed consistent results with biopsy features showing sub epidermal split with eosinophils. 1 out of 19 cases showed nonspecific features for which DIF was done and showed homogenous linear deposits of IgG and C3 in the basement membrane zone Pemphigus foliaceous cases in our study are 6, 5 ( 83.3\%) cases showed consistent results with histology. One was diagnosed with help of immunoflourescence.Pemphigus vulgaris and foliaceous can be differentiated by histological features and DIF. Pemphigus vegetans cases are correlated successfully both clinically and histopathologically and are differentiated from pemphigus vulgaris.

Dermatitis Herpetiformis is 20-40 years and occasionally occurs in children.17 The histopathological findings noted were subepidermal bulla with neutrophils and a few lymphocytes. In our study total 5 cases are studied clinically and correlated with histological findings. 4 out $5(83.3 \%)$ consistent results are obtained. All the 3 clinically dignosed CBDC cases, were histopathologically consistent with CBDC our study showed consistent results in correlation between clinical diagnosis with histopathological findings in majority of cases except in few cases where diagnosis was correlated with direct immunoflourescence. there was 95.5\% correlation between clinical findings with histological features in our study with error of $4.5 \%$. where immunoflouresecnce was done for the diagnosis of remaining cases.

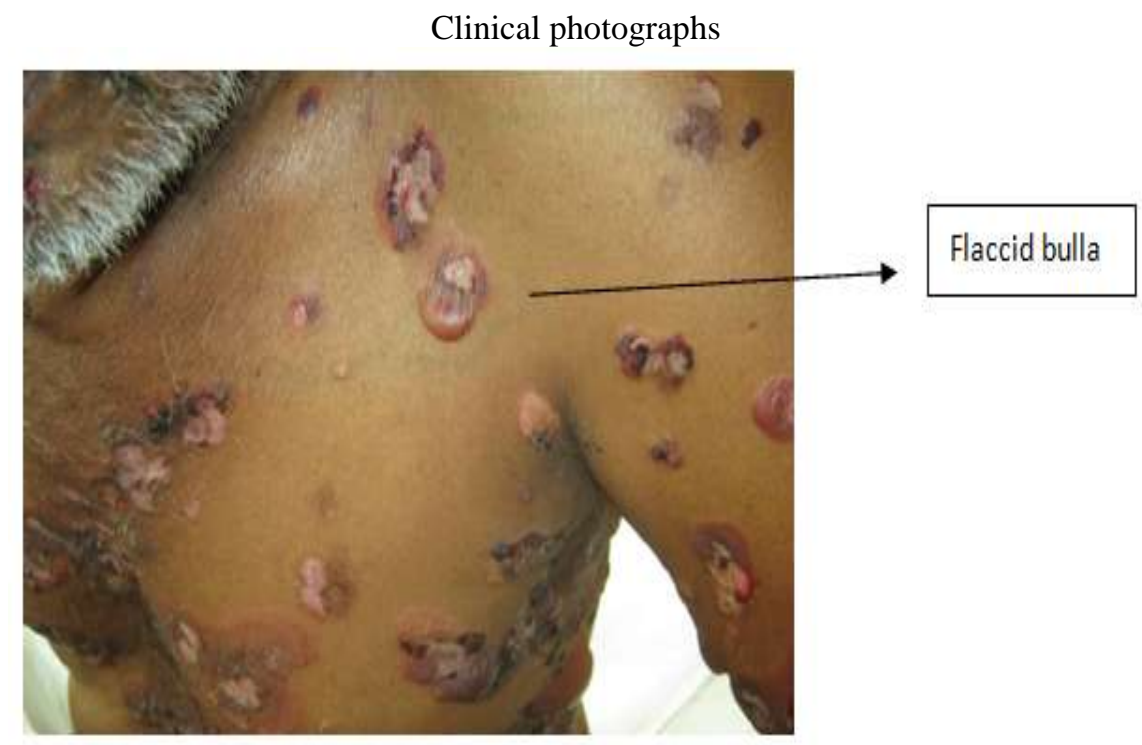

Fig: 1- Pemphigus Vulgaris Showing Flaccid Bulla

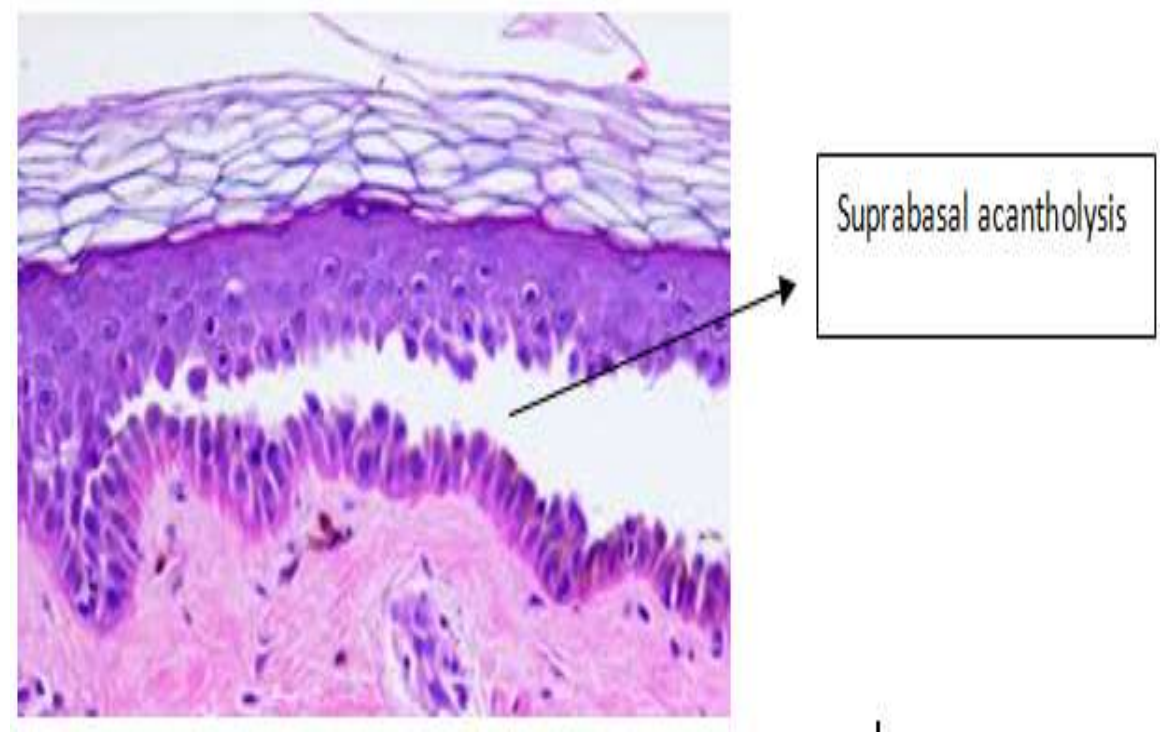

Fig:2 -Pemphigus Vulgaris Showed Intraepidermal Blister ,Suprabasal Acantholysis 


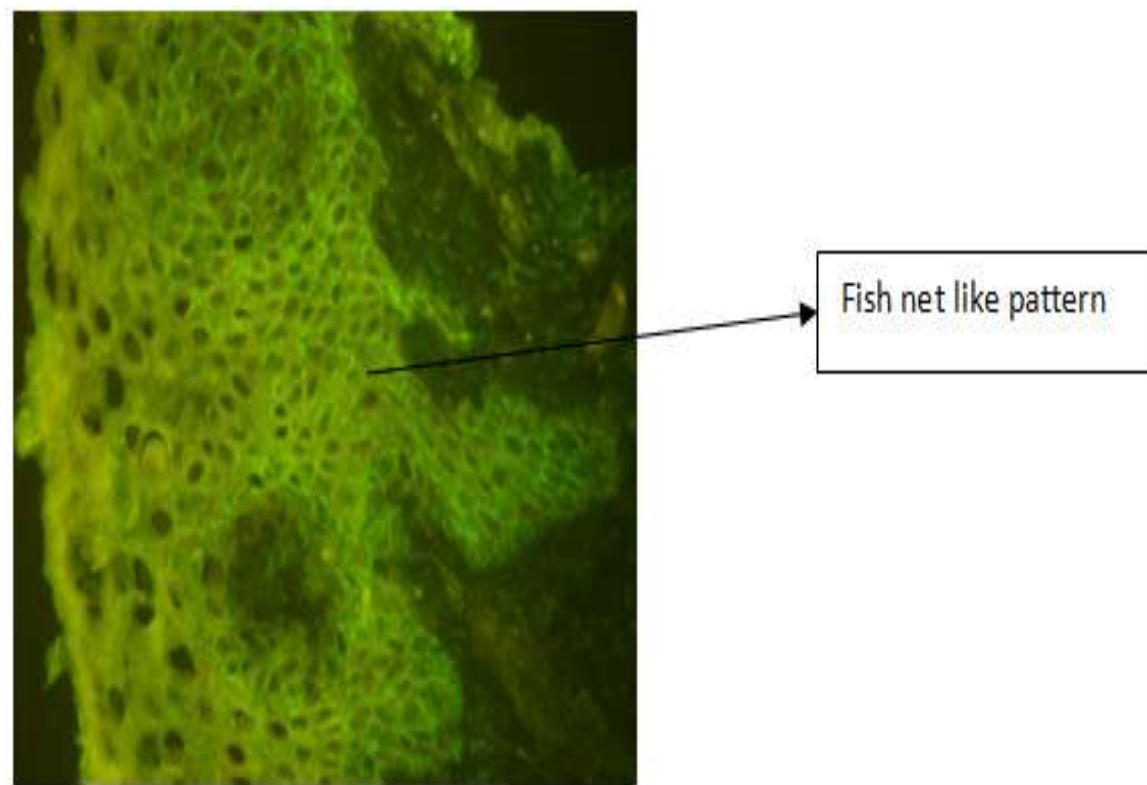

FIg 3: Direct Immunofluroscence Of Pemphigus Vulgaris Showed Lace/Fishnet Pattern Of Igg,Ics

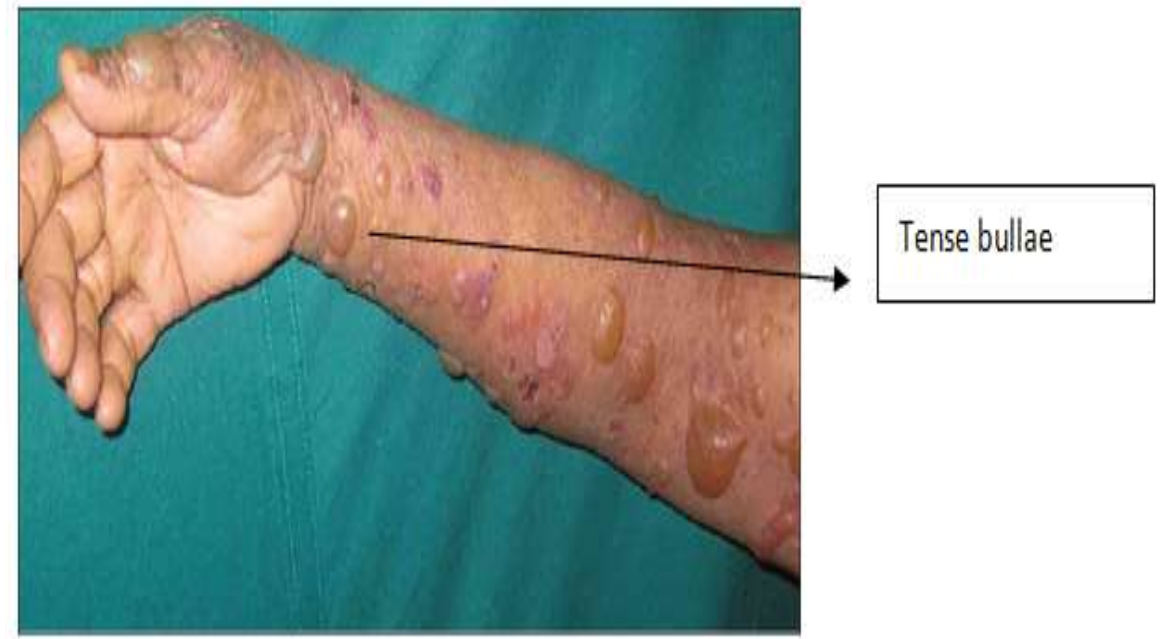

Fig : 4 - Tense Bullae In Bullous Pemphigoid Patients

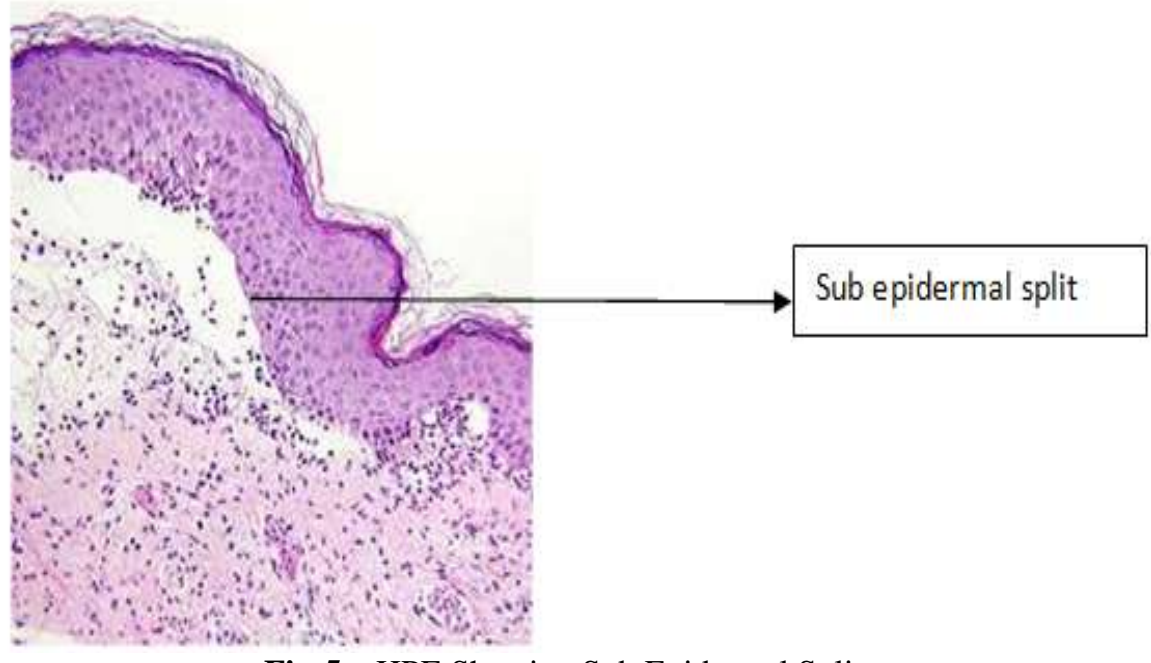

Fig:5 - HPE Showing Sub Epidermal Split 


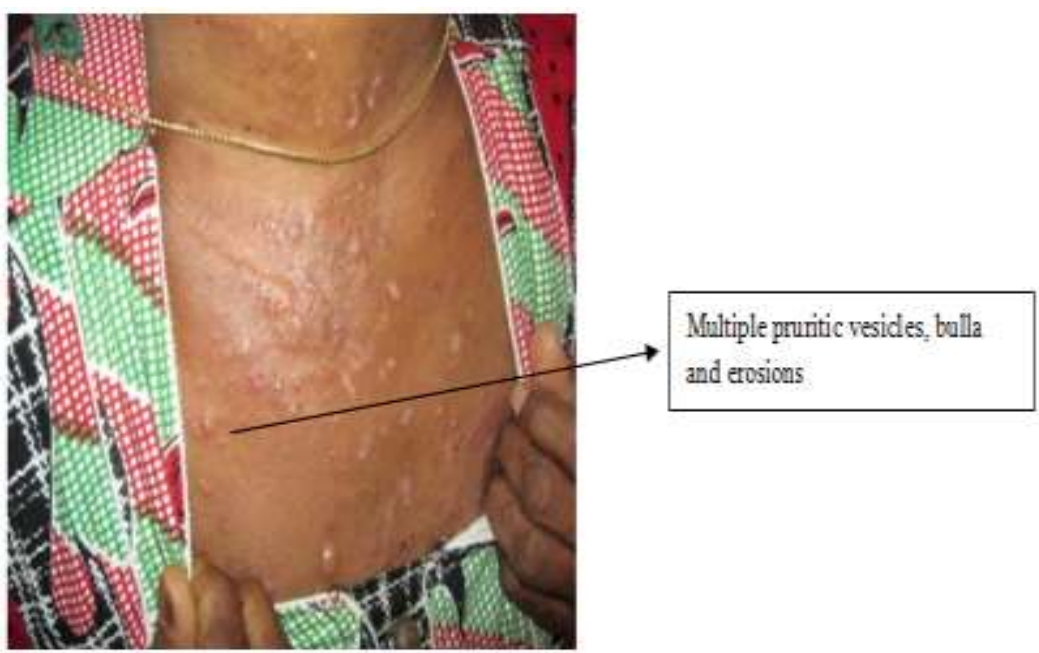

Fig:6 - Vesicles And Bulla In Dermatitis Herpetiformis Patient

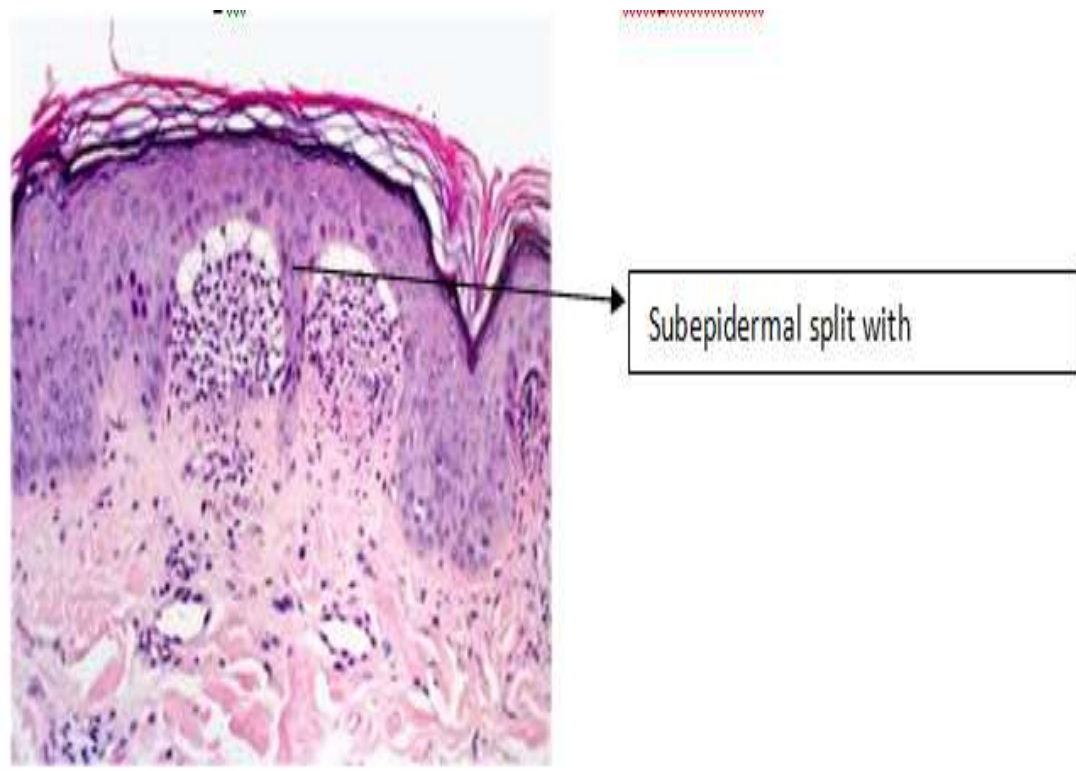

Fig: 7- HPE Of Dermatitis Herpetiformis

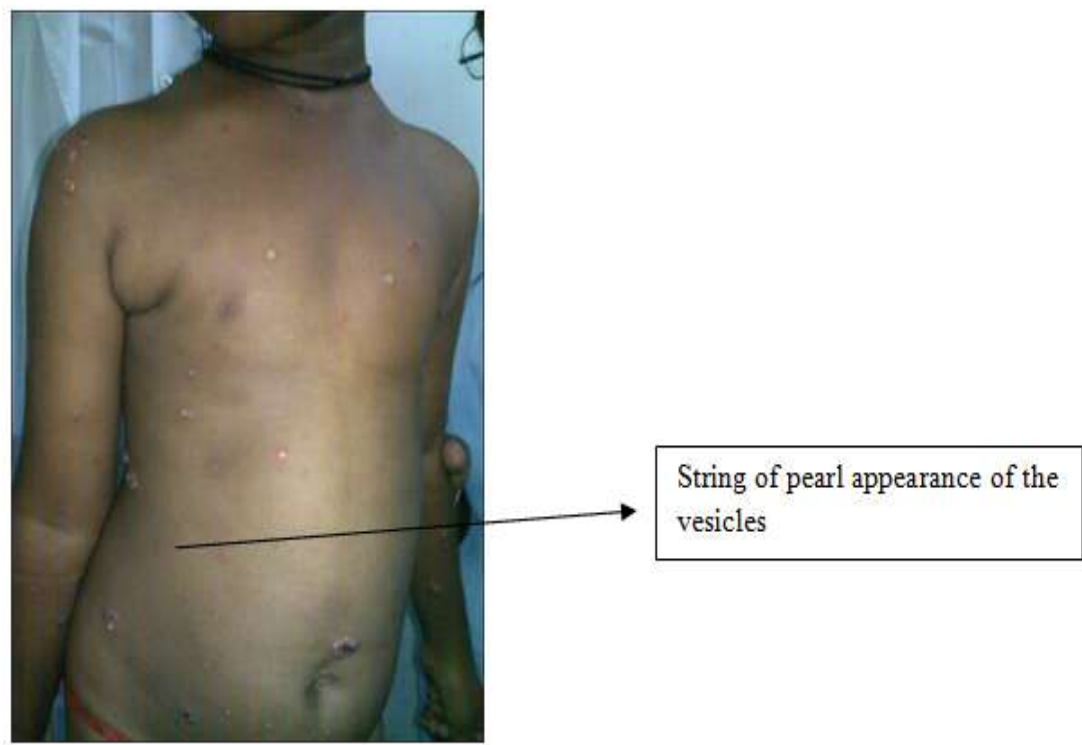

Fig: 8 - A child with chronic bullous disorder of childhood 


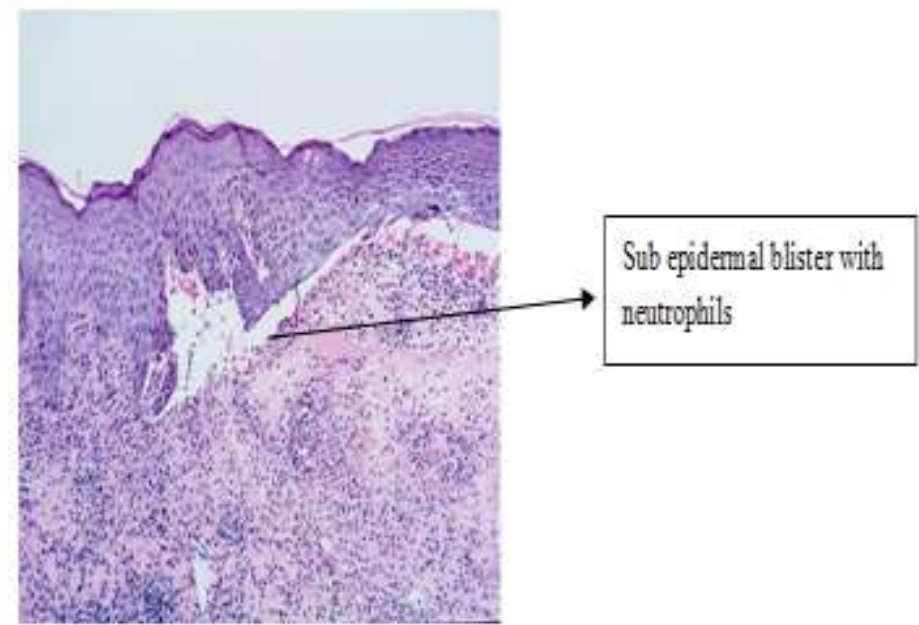

Fig: 9 - Hpe Of Cbdc

\section{Conclusion}

The association of clinical and histopathological features in the study helped to arrive at the diagnosis in most cases with significant association. This increases the chance of making diagnosis with help of simple investigations without the need for expensive investigations like DIF. But Immunofluorescence study done in a few cases helped in confirming the diagnosis where histopathology and clinical features alone were inconclusive.

\section{References}

[1]. Khandhari KC, Paricha JS. Pemphigus in Northern India Clinical studies in 34 patients. Indian J Dermatol Venereol. 1965; 31: 6270.

[2]. Arya SR, Valand AG, Krishna K A. Clinicopathological study of 70 cases of pemphigus. Indian J Dermatol Venereol Leprol. 1999; 168-71.

[3]. Shafi M, Khatri ML, Mashina M, Ben-Ghazeil M: Pemphigus A Clinical study of 109 cases from Tripoli, Libya. Indian J Dermatol Venereol Leprol. 1994; 60: 140-3.

[4]. Fernandez JC, Dharani JB, Desai SC. A Study of 100 cases of pemphigus - clinical features. Indian J Dermatol Venereol. 1970; 36 : $1-11$.

[5]. 5. Swarnalatha G, Reddy JS. Direct fluorescence on Tzanck smears: A rapid test to confirm Pemphigus. Indian J Dermatol Venereol Leprol. 2001;67:218

[6]. Lebe B, Gul Niflioglu G, Seyrek S, Ellidokuz H. Evaluation of clinical and histopathologic/direct immunofluorescence diagnosis in autoimmune vesicobullous dermatitis. Utility of direct immunofluorescence . Turk Patoloji Derg 2012;28:11-6.

[7]. Sitaru C, Zillikens D. Mechanisms of blister induction by autoantibodies.Exp Dermat 2005;14:861-75.

[8]. Jung M, Kippes W, Messer G, Zillikens D, Rzany B. Increased risk of bullous pemphigoid in male and very old patients: A populationbased study on incidence. J Am Acad Dermatol 1999;41:266-8.

[9]. Leena JB, Chandrashekhar M, Vijaya B, Sunila R, Manjunath GV. A clinicopathological study of immunobullous lesions of the skin. Adv Lab Med Int 2012;2:49-60

[10]. Micali G, Musumeci ML, Nasca MR. Epidemiologic analysis and clinical course of 84 consecutive cases ofpemphigus in eastern Sicily. Int J Dermatol 1998;37:197-200. 